\title{
Theoretical Study of the Electron Temperature in the High-Latitude Ionosphere for Solar Maximum and Winter Conditions
}

\author{
R. W. SCHUNK, J. J. SoJKA, AND M. D. BOWLINE
}

Center for Atmospheric and Space Sciences, Utah State University, Logan

\begin{abstract}
The electron temperature $\left(T_{e}\right)$ variation in the high-latitude ionosphere at altitudes between 120 and 800 $\mathrm{km}$ has been modeled for solar maximum, winter solstice, and strong magnetic activity conditions. The calculated electron temperatures are consistent with the plasma densities and ion temperatures computed from a time-dependent ionospheric model. Heating rates for both solar EUV and auroral precipitation were included. In general, the predicted UT variation of the electron temperature that results from the displacement between the magnetic and geographic poles is only a few hundred degrees. However, in sunlit trough regions, $T_{e}$ hot spots develop, and these hot spots show a marked UT variation, by as much as $2500 \mathrm{~K}$. The dominant parameter controlling the $T_{e}$ variation above $200 \mathrm{~km}$ is the magnetospheric heat flux into the ionosphere, which is essentially unknown. For realistic values of the magnetospheric heat flux, the maximum electron temperature ranges from 5000 to $10,000 \mathrm{~K}$ at $800 \mathrm{~km}$. A magnetospheric heat flux is particularly effective in enhancing trough electron temperatures. In general, the electron heat flux at high altitudes is uniquely related to the electron temperature and gradient, except on auroral field lines where thermoelectric heat flow is important.
\end{abstract}

\section{INTRODUCTION}

During the last several years, we have developed a comprehensive model of the convecting high-latitude ionosphere in order to determine the extent to which various chemical and transport processes affect the ion temperature, ion composition, and electron density at $F$ region altitudes [cf. Schunk and Raitt, 1980; Sojka et al., 1979, 1981a; Schunk and Sojka, 1982a]. Our numerical model produces time-dependent, three-dimensional distributions for the ion temperature and the ion $\left(\mathrm{NO}^{+}, \mathrm{N}_{2}^{+}, \mathrm{O}_{2}^{+}\right.$, $\mathrm{N}^{+}, \mathrm{O}^{+}, \mathrm{He}^{+}$) and electron densities. The model takes account of field-aligned diffusion, cross-field electrodynamic drifts, thermospheric winds, polar wind escape, energy-dependent chemical reactions, neutral composition changes, ion production due to solar EUV radiation and auroral precipitation, ion thermal conduction, ion diffusion-thermal heat flow, and local heating and cooling processes. Our model also takes account of the offset between the geomagnetic and geographic poles.

In this investigation, we have improved our high-latitude ionospheric model by including the electron energy equation so that we can study the electron temperature variations in the high-latitude $F$ region. The adopted energy equation takes account of thermal conduction, thermoelectric transport, Joule heating, heating due to photoelectrons and auroral electrons, collisional coupling to the thermal ions, and both elastic and inelastic cooling to the neutrals.

Although a significant effort has been devoted to studying the electron temperature behavior at middle and low latitudes, in comparison much less effort has been directed toward studying the $T_{e}$ behavior at high latitudes [cf. Schunk and Nagy, 1978]. However, during the last decade, certain trends have been clearly established with the aid of both satellite and groundbased measurements. For example, $T_{e}$ is higher on the dayside than on the nightside; $T_{e}$ is generally higher in the auroral oval than outside the oval; the maximum values of $T_{e}$ are usually obtained in the cusp; $T_{e}$ is typically elevated in the trough; and

Copyright 1986 by the American Geophysical Union.

Paper number 6A8422.

$0148-0227 / 86 / 006 \mathrm{~A}-8422 \$ 05.00$
$T_{e}$ is significantly elevated during geomagnetic storms and substorms.

Recently, interest in the $T_{e}$ behavior at high latitudes has been renewed with the measurements of extremely high electron temperatures $\left(T_{e} \gtrsim 5000 \mathrm{~K}\right)$ and temperature gradients $\left(d T_{e} / d z\right.$ $\approx 8-12 \mathrm{~K} / \mathrm{km}$ ) at altitudes below $500 \mathrm{~km}$ [Kofman and Wickwar, 1984]. These temperatures and temperature gradients were measured with the Sondrestrom radar in the vicinity of both the late morning and early afternoon convection reversals. Very high electron temperatures $\left(T_{e} \sim 4000-6000 \mathrm{~K}\right)$ were also measured near $500 \mathrm{~km}$ in red aurora at both Chatanika and Sondrestrom [Wickwar and Kofman, 1984]. In addition, DE 2 satellite measurements indicate very high electron temperatures $\left(T_{e} \approx 8000-10,000 \mathrm{~K}\right)$ and temperature gradients $\left(d T_{e} / d z \approx 8\right.$ $\mathrm{K} / \mathrm{km}$ ) at $800 \mathrm{~km}$ in the cusp region [Curtis et al., 1985].

In order to determine how such high electron temperatures and temperature gradients might develop and in order to elucidate the basic processes controlling $T_{e}$ behavior at high latitudes, we have used our improved ionospheric model to obtain the first large-scale electron temperature distribution at high latitudes. The calculations were performed for one set of conditions: solar maximum, winter solstice, and strong magnetic activity.

\section{IONOSPHERIC MODEL}

Our mid-high-latitude model contains a plasma convection model and an ionospheric-atmospheric composition model. The model was initially developed as a mid-latitude, multi-ion $\left(\mathrm{NO}^{+}, \mathrm{O}_{2}^{+}, \mathrm{N}_{2}^{+}, \mathrm{O}^{+}\right)$model by Schunk and Walker [1973]. The model was extended to include high-latitude effects, such as plasma convection and auroral precipitation, by Schunk et al. $[1975,1976]$. A further extension to include $\mathrm{N}^{+}$and an updating of the photochemistry is described by Schunk and Raitt [1980]. The addition of the plasma convection model, which allows us to cover the entire high-latitude region, is described by Sojka et al. $[1979,1980]$. More recently, the model has been extended to include ion thermal conduction and diffusion-thermal heat flow, so that the ion temperature is now rigorously calculated at all altitudes between 120 and $800 \mathrm{~km}$ [Schunk and Sojka, $1982 a]$. 
TABLE 1. Thermal Electron Cooling Processes

\begin{tabular}{lcl}
\hline \multicolumn{1}{c}{ Process } & $\begin{array}{c}\text { Equation in the } \\
\text { Work by Schunk } \\
\text { and Nagy [1978] }\end{array}$ & \multicolumn{1}{c}{ Source } \\
\hline $\mathrm{N}_{2}$ rotation & $(18)$ & Dalgarno [1968] \\
$\mathrm{O}_{2}$ rotation & $(19)$ & Dalgarno [1968] \\
$\mathrm{N}_{2}$ vibration & $(20)$ & Stubbe and Varnum $[1972]$ \\
$\mathrm{O}_{2}$ vibration & $(23)$ & Prasad and Furman $[1973]$ \\
$\mathrm{O}$ fine structure & $(26)$ & Hoegy [1976] \\
$\mathrm{O}^{1}$ D) & $(34)$ & Henry et al. $[1969]$ \\
$\mathrm{N}_{2}$ elastic & $(43 a)$ & Banks $[1966]$ \\
$\mathrm{O}_{2}$ elastic & $(43 b)$ & Banks [1966] \\
$\mathrm{O}$ elastic & $(43 c)$ & Henry and McElroy [1968] \\
He elastic & $(43 d)$ & Banks [1966] \\
$\mathrm{H}$ elastic & $(43 e)$ & Banks [1966] \\
\hline
\end{tabular}

With the mid-high-latitude ionospheric model, we follow flux tubes of plasma as they convect through a moving neutral atmosphere. Altitude profiles of the ion temperature and $\mathrm{NO}^{+}$, $\mathrm{O}_{2}^{+}, \mathrm{N}_{2}^{+}, \mathrm{O}^{+}, \mathrm{N}^{+}$, and $\mathrm{He}^{+}$densities are obtained by solving the appropriate continuity, momentum, and energy equations including numerous high-latitude processes. These equations are solved over the altitude range from 120 to $800 \mathrm{~km}$, with chemical equilibrium at $120 \mathrm{~km}$ and a specified plasma escape flux at $800 \mathrm{~km}$ being the lower and upper boundary conditions, respectively. In this study, the escape flux at $800 \mathrm{~km}$ was set to zero.

In this study, we have improved our high-latitude ionospheric model by including the electron energy equation so that we can study the electron temperature variations in the high-latitude $F$ region. The adopted energy equation takes account of thermal conduction, thermoelectric transport, Joule heating, heating due to both photoelectrons and auroral electrons, collisional coupling to the thermal ions, and both elastic and inelastic cooling to the neutrals. In the paragraphs that follow, we briefly discuss the electron energy equation and the adopted heating and cooling processes.

\subsection{Electron Energy Equation}

The electron energy equation can be written in the following form [Schunk and Nagy, 1978].

$$
\begin{aligned}
& \frac{3}{2} \mathbf{N}_{e} k \frac{\partial T_{e}}{\partial T}=\sin ^{2} I \frac{\partial}{\partial z}\left(K^{e} \frac{\partial T_{e}}{\partial z}\right) \\
& +\sin I \frac{k J_{e}}{e} \frac{3}{2}\left(1+\frac{5}{3} \frac{g_{\sigma_{o}}}{g_{\mu_{o}}}\right) \frac{\partial T_{e}}{\partial z} \\
& +\sin I \frac{k J_{e}}{e}\left[\frac{1}{J_{e}} \frac{\partial J_{e}}{\partial z}\left(1+\frac{5}{2} \frac{g_{\sigma_{o}}}{g_{\mu_{o}}}\right)-\frac{1}{N_{e}} \frac{\partial N_{e}}{\partial z}\right] T_{e} \\
& +\frac{J_{e}^{2}}{\sigma_{e}}+\sum Q_{e}-\sum L_{e}
\end{aligned}
$$

where $T_{e}$ is the electron temperature, $J_{e}$ is the electron current, $N_{e}$ is the electron density, $\sigma_{e}$ is the electrical conductivity, $K^{e}$ is the electron thermal conductivity, $\Sigma Q_{e}$ is the sum of the electron heat rates, $\Sigma L_{e}$ is the sum of the electron cooling rates, $t$ is time, $z$ is the vertical coordinate, $k$ is Boltzmann's constant, $e$ is the magnitude of the electron charge, and $I$ is the magnetic field dip angle.

In deriving equation (1) we have used

$$
\mathbf{J}_{e}=-e N_{e} \mathbf{U}_{e}
$$

$$
\mathbf{q}_{e}=-\beta_{e} \mathbf{J}_{e}-K^{e} \nabla T_{e}
$$

where the conductivities are given by

$$
\begin{gathered}
\sigma_{e} \stackrel{\searrow}{=} \frac{N_{e} e^{2}}{M_{e}} \frac{1}{\left\langle\nu_{g}\right\rangle g_{\sigma_{\circ}}} \\
\beta_{e}=\frac{5}{2} \frac{k T_{e}}{e} \frac{g_{\sigma_{\circ}}}{g_{\mu_{o}}} \\
K^{e}=\frac{5 N_{e} k^{2} T_{e}}{M_{e}} \frac{1}{\left\langle\nu_{g}\right\rangle}\left[\frac{1}{g_{k_{\circ}}}-\frac{\mathrm{g}_{\sigma_{o}}}{2 g_{\tau_{o}} g_{\mu_{\circ}}}\right]
\end{gathered}
$$

where $U_{e}$ is the electron drift velocity, $\mathbf{q}_{e}$ is the heat flow vector, $M_{e}$ is the electron mass, $\left\langle\nu_{g}\right\rangle=\left\langle\nu_{e i}\right\rangle+\Sigma_{n}\left\langle\nu_{e n}\right\rangle$ is the average collision frequency with ions and neutrals, and $g_{\sigma_{0}}, g_{\tau_{0}}, g_{\mu_{0}}$, and $g_{k_{\circ}}$ are correction factors which account for the variation with velocity of the electron-neutral particle collision frequency as well as for electron-ion and electron-electron effects. The $g$ and $\langle\nu\rangle$ are given by Schunk and Walker [1970] and are not repeated here.

Several assumptions are implicit in equations (1) to (6). We have assumed that $\mathbf{J}_{e}$ and $\mathbf{q}_{e}$ only flow along the geomagnetic field and that the different physical quantities vary only in the vertical ( $z$ ) direction. Also, the electron conductivities are valid only for a collision-dominated plasma; i.e., the electron mean free path must be much less than the electron temperature scale length. Such a condition is generally satisfied in the ionosphere at $F$ region altitudes.

For ionospheric applications, the electron thermal conductivity takes a particularly simple form [cf. Schunk and Nagy, 1978],

$$
K^{e}=\frac{7.7 \times 10^{5} T_{e}^{5 / 2}}{1+3.22 \times 10^{4}\left(T_{e}^{2} / N_{e}\right) \Sigma_{n} N_{n}\left\langle q_{D}\right\rangle_{n}} \mathrm{eV} \mathrm{cm}^{-1} \mathrm{~s}^{-1} \operatorname{deg}^{-1}(7)
$$

where $N_{n}$ is the neutral density and $\left\langle q_{D}\right\rangle_{n}$ is the average momentum transfer cross section for neutral species $n$; the appropriate values are given by equations (41a)-(41e) of Schunk and Nagy [1978].

\subsection{Heating and Cooling Rates}

A crucial input for the electron energy equation is the volume heating rate. Significant heating occurs in sunlit regions due to photoelectrons and in the auroral oval due to precipitating electrons. Several previous studies have described these heating rates (see review by Schunk and Nagy [1980] and references therein). For the solar EUV heating rate, we adopted the model of P. G. Richards [private communication, 1984; Richards and Torr, 1984]. This model computes the electron volume heating rate as a by-product of the EUV-produced photoelectron flux. For the auroral heating rate, we adopted the profile computed by Rees et al. [1971], but the profile was scaled to an auroral electron energy flux of $1 \mathrm{erg} \mathrm{cm}^{-2} \mathrm{~s}^{-1}$, which is appropriate for the present study.

At middle and low latitudes, the electron temperature is typically greater than the ion temperature, and therefore, the ions act as a heat sink for the thermal electrons. However, at high latitudes the ions can be hotter than the electrons, and hence, act as a heat source for the electrons. The electron-ion energy coupling term we adopted is given by Schunk and Nagy $[1978$, equation 48], but the expression has been extended to include electron interactions with $\mathrm{NO}^{+}, \mathrm{O}_{2}^{+}, \mathrm{N}_{2}^{+}, \mathrm{O}^{+}, \mathrm{N}^{+}$, and $\mathrm{He}^{+}$.

The thermal electrons cool as a result of both elastic an inelastic collisions with the neutrals in the upper atmosphert 

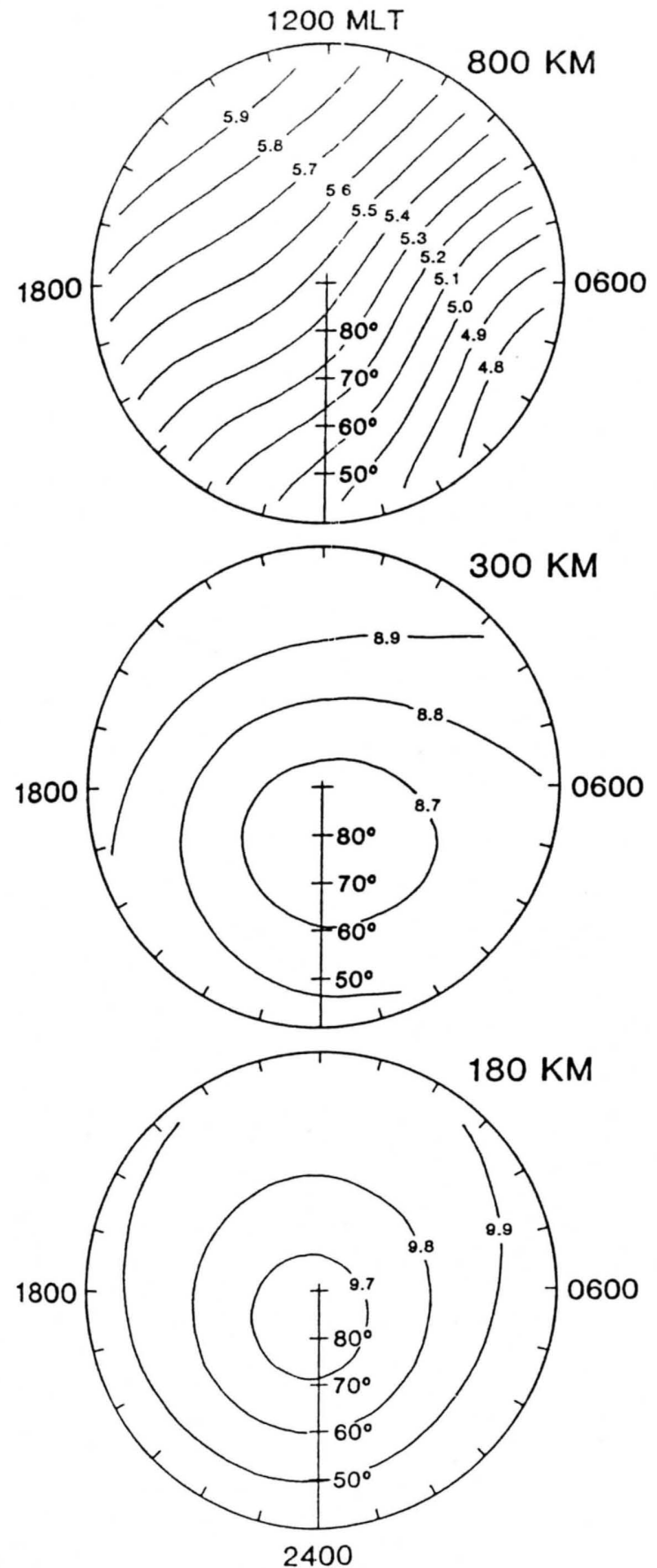

Fig. 1. Contours of $\log _{10}[\mathrm{O}]$ as a function of magnetic latitude and MLT at three altitudes for 1700 UT. The densities $\left(\mathrm{cm}^{-3}\right)$ were obtained from the MSIS atmospheric model [Hedin et al., 1977a, b].

The cooling processes that we included are listed in Table 1 . Also given in Table 1 are the equation numbers in the work by Schunk and Nagy [1978] for the expressions we adopted and the original sources of the cooling rates.

\subsection{Numerical Solution}

The electron energy equation (1) is a nonlinear, second-order, partial differential equation for the electron temperature. This equation was solved by first linearizing in time and then using a standard finite difference scheme [Crank and Nicolson, 1947]. In general, the electron energy equation was solved self- consistently with the ion continuity, momentum, and energy equations. The accuracy of the results was determined by checking the energy conservation. Adequate convergence was obtained with a 4-km space step.

At the lower boundary, heat flow processes are negligibly small and the electron temperature was calculated by equating local heating and cooling rates. At the upper boundary, the electron heat flux was specified so that we could study the effect on the electron temperature of a high-altitude heat source.

\section{GeOPHYSICAL CoNDITIONS}

For this initial electron temperature study, we selected solar maximum, winter solstice, and strong geomagnetic activity conditions. During the last solar maximum period, electron temperatures in excess of $6000 \mathrm{~K}$ were frequently observed by both ground-based radars and satellites in the high-latitude ionosphere. As noted earlier, we hope to obtain an understanding of the processes that act to produce such high electron temperatures. Winter solstice was selected because there is both a pronounced UT variation of the ionosphere and a large variation in electron density over the polar region at this time. Strong geomagnetic activity conditions were selected so that the effects of transport processes on the electron temperature distribution could be elucidated.

One of the important inputs to our ionospheric model is the plasma convection pattern. For this study, we selected an asymmetric two-cell pattern with enhanced plasma flow in the dusk sector. The pattern is of the type developed by Volland $[1975,1978]$, but modified in the manner described by Sojka et $a l$. [1981b]. A total cross-tail magnetospheric potential of $90 \mathrm{kV}$ was selected, which roughly corresponds to a $K p$ of 5 . For our asymmetric potential distribution, $75 \mathrm{kV}$ were distributed across the dusk cell and $15 \mathrm{kV}$ across the dawn cell. Such a distribution produces horizontal convection velocities of up to $2 \mathrm{~km} / \mathrm{s}$ at ionospheric altitudes in the strong convection cell. The convection model characteristics also included a circular polar cap with a $17^{\circ}$ radius, but the center was offset from the magnetic pole by $3^{\circ}$ in the antisunward direction. In the polar cap, the electric field was aligned parallel to the dawn-dusk meridian. Equatorward of the polar cap, the electric field decreased to zero at the equator as the inverse of the sine of colatitude to the fourth power. This convection pattern is the same one we used in several previous studies [Sojka et al., 1981b, 1982; Schunk and Sojka, 1982b; Sojka and Schunk, 1983]. Further details of the plasma convection characteristics are given by Sojka et al. [1981b]. A similar convection pattern was also used in a comparison of model predictions with Millstone Hill incoherent scatter observations [Sojka et al., 1983]. This paper shows how such a convection pattern appears to a corotating observer at the longitude of Millstone Hill.

In addition to the plasma convection pattern, our ionospheric model requires several other inputs, including a neutral atmosphere, a neutral wind pattern, an auroral oval, and a Birkeland current system. For the neutral atmosphere, we adopted the mass spectrometer and incoherent scatter (MSIS) model developed by Hedin et al. [1977a], and we used an F10.7 of 150 and an $A p$ of 35 to reflect solar maximum and strong geomagnetic activity, respectively. For our neutral wind pattern, we adopted a modified form of the thermospheric wind pattern given by Murphy et al. [1976]. Briefly, the neutral wind over the polar cap blows from 1300 to $0100 \mathrm{LT}$. In darkness the wind speed is 200 $\mathrm{m} / \mathrm{s}$, while in sunlight it is significantly smaller (see Sojka et al. 


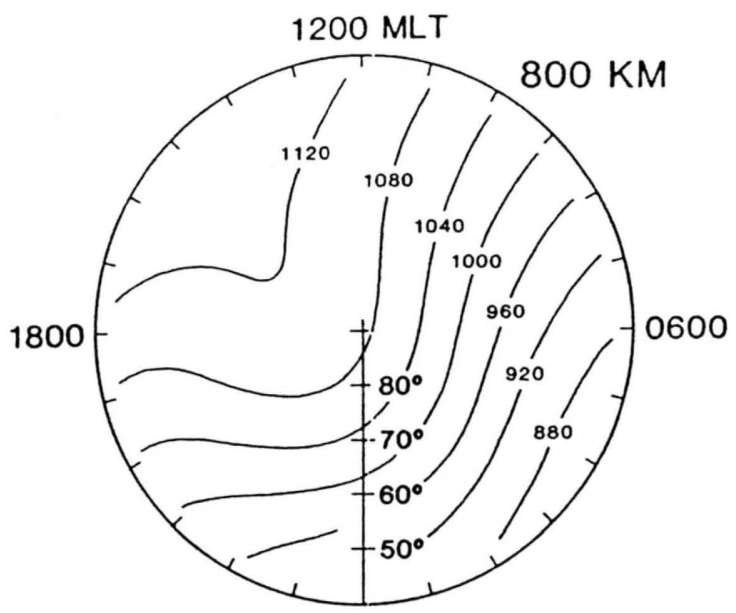

density, the ion temperature, and the volume heating rate due to photoelectrons and precipitating auroral electrons. Therefore, these parameters will be discussed in the following paragraphs so that their influence on $T_{e}$ can be easily determined.

Figure 1 shows contours of the atomic oxygen density [O] at three altitudes for $1700 \mathrm{UT}$. At low altitudes, below $300 \mathrm{~km}$, the density has a minimum near the magnetic pole and varies by only a factor of two between $50^{\circ}$ and the pole. In sharp contrast, at high altitudes (top panel) the density has a maximum at low latitudes around $1500 \mathrm{MLT}$ and decreases by over an order of magnitude across the polar cap to $50^{\circ}$ at $0400 \mathrm{MLT}$. The density decreases exponentially with altitude with a scale height that depends on the neutral temperature.
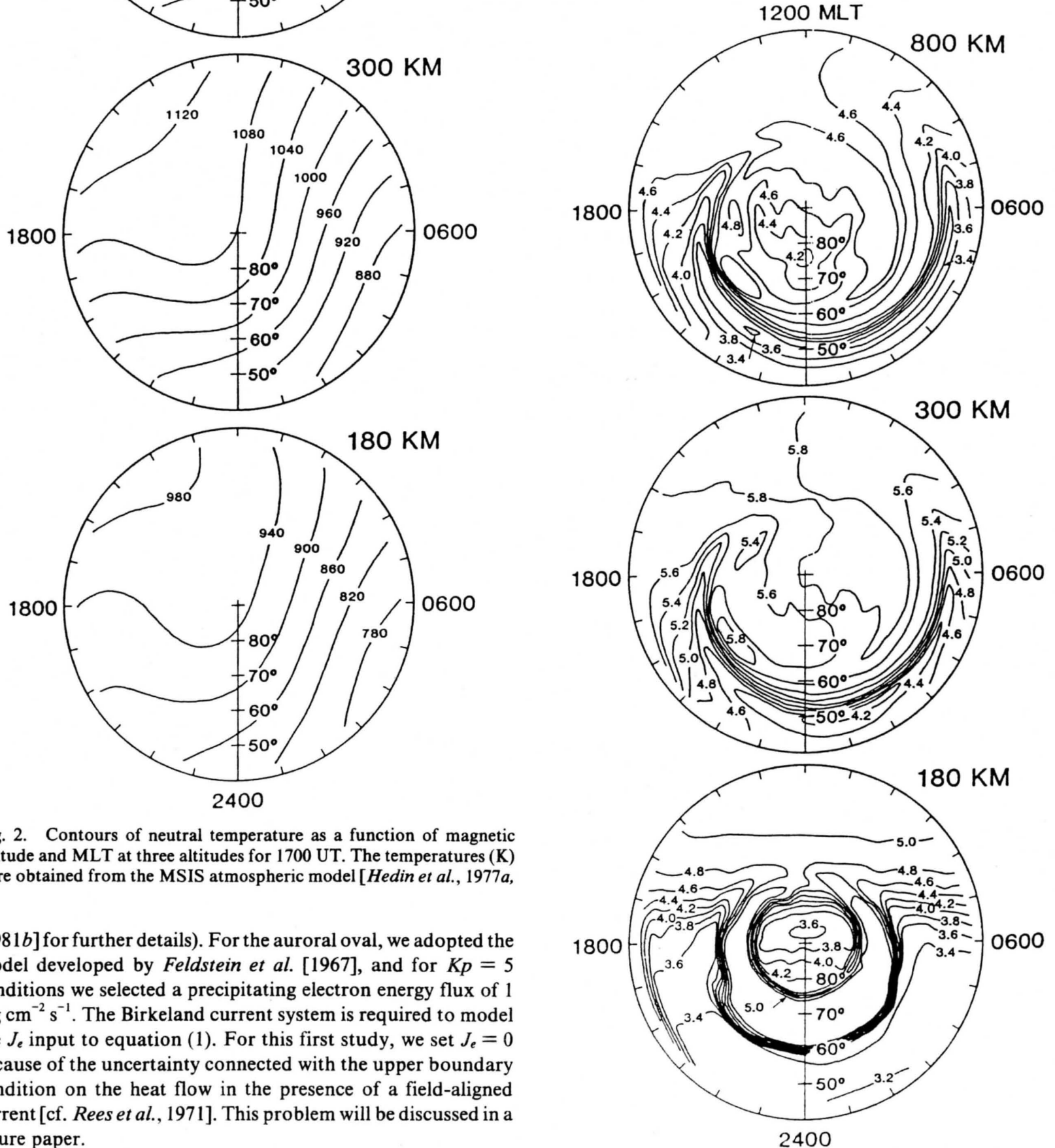

Fig. 2. Contours of neutral temperature as a function of magnetic latitude and MLT at three altitudes for $1700 \mathrm{UT}$. The temperatures (K) were obtained from the MSIS atmospheric model [Hedin et al., 1977a, b].

[1981b] for further details). For the auroral oval, we adopted the model developed by Feldstein et al. [1967], and for $K p=5$ conditions we selected a precipitating electron energy flux of 1 $\mathrm{erg} \mathrm{cm} \mathrm{cm}^{-2} \mathrm{~s}^{-1}$. The Birkeland current system is required to model the $J_{e}$ input to equation (1). For this first study, we set $J_{e}=0$ because of the uncertainty connected with the upper boundary condition on the heat flow in the presence of a field-aligned current [cf. Rees et al., 1971]. This problem will be discussed in a future paper.

The electron temperature is strongly affected by the neutral atomic oxygen density, the neutral temperature, the electron

Fig. 3. Contours of $\log _{10} N_{e}\left(\mathrm{~cm}^{-3}\right)$ as a function of magnetic latitude and MLT at three altitudes for 1700 UT. 
Figure 2 shows the neutral temperature plotted in the same format as Figure 1 for the same altitudes and UT. At all three altitudes, $T_{n}$ has a maximum at low latitudes around 1500 MLT and decreases over the pole to a minimum around $0500 \mathrm{MLT}$. This variation is similar to that of [O] at high altitudes owing to the scale height dependence of [O] above $300 \mathrm{~km}$. $T_{n}$ varies by about $200 \mathrm{~K}$ across the high-latitude ionosphere, with a maximum value of about $1120 \mathrm{~K}$. Above $300 \mathrm{~km}, T_{n}$ is essentially constant with altitude.

Figure 3 shows contours of $\log _{10} N_{e}$ at three altitudes for 1700 UT. At this UT, more of the polar cap is sunlit than at any other time of the day; the terminator extends from 1800 to 0700 MLT.
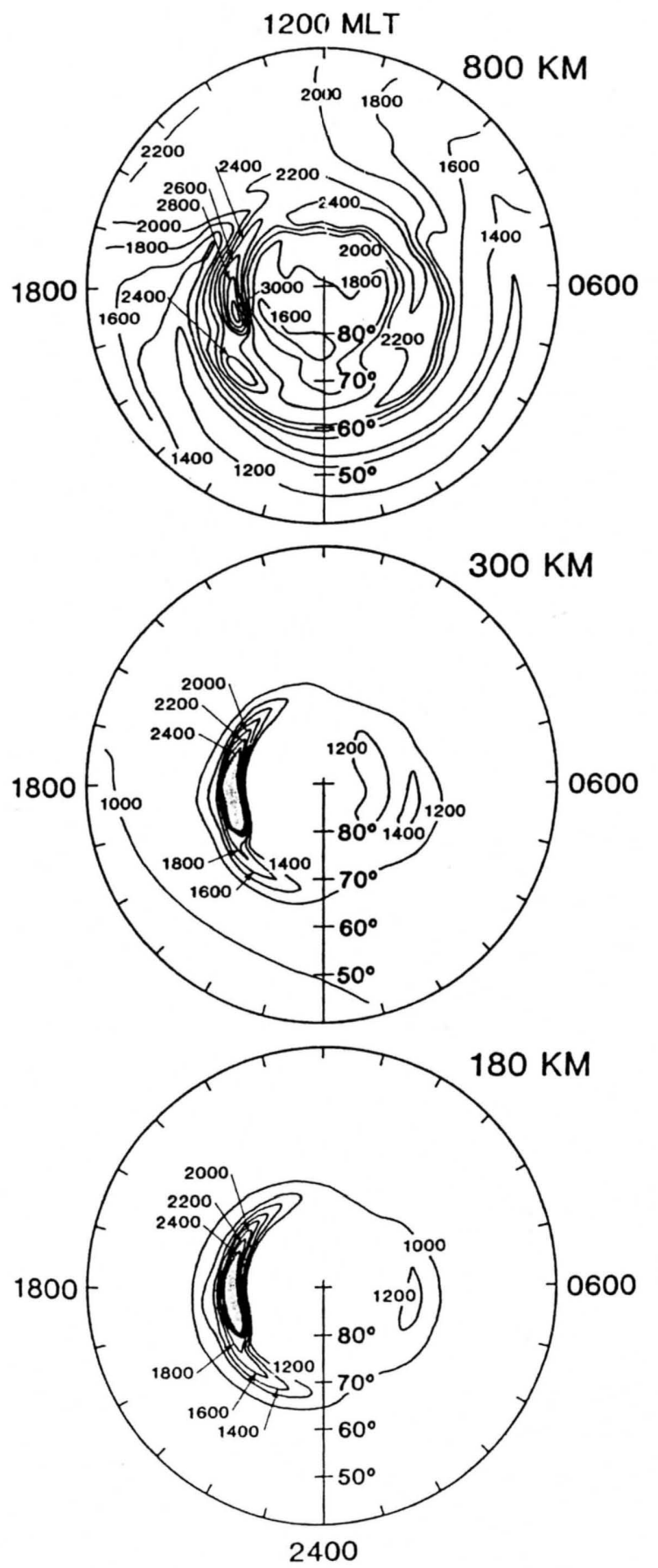

Fig. 4. Contours of ion temperature as a function of magnetic latitude and MLT at three altitudes for 1700 UT.

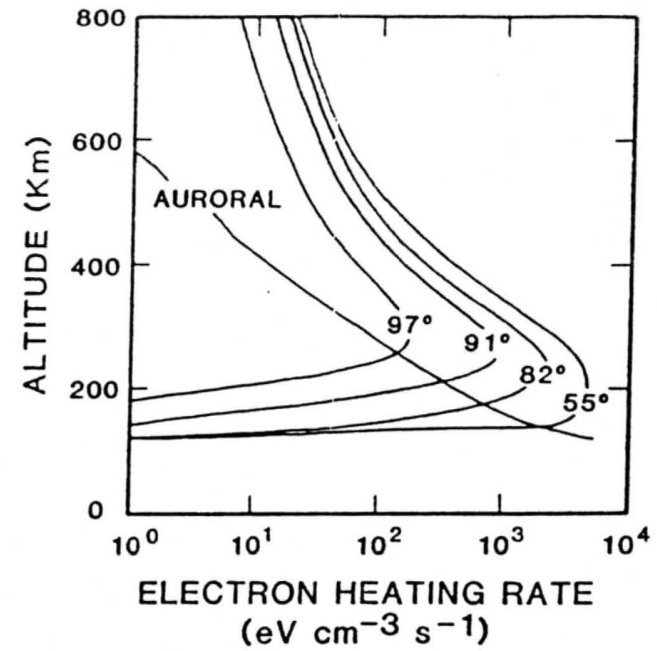

Fig. 5. Electron heating rate as a function of altitude for both auroral and solar EUV sources. The auroral heating rate was adopted from Rees et al. [1971]. The EUV heating rate is shown for several solar zenith angles and was calculated using the method described by Richards and Torr [1984].

At $180 \mathrm{~km}, N_{e}$ reflects the balance between production and loss with both the auroral oval and terminator being discernible via the gradients in density. The auroral oval is a region where the density is about $10^{5} \mathrm{~cm}^{-3}$, while the terminator is a region where the density decreases smoothly from $10^{5}$ to below $5 \times 10^{3} \mathrm{~cm}^{-3}$. At this altitude the density varies by more than two orders of magnitude.

The $N_{e}$ variation at $300 \mathrm{~km}$ is considerably more complex. The highest densities are still associated with the oval and sunlight, but transport effects have smeared these regions. A region of high density has been transported into the polar cap from the dayside, producing a "tongue of ionization." In the eveningmidnight-morning sector equatorward of the oval, the midlatitude trough is well defined. The increase in density equatorward of the trough is due to the upward plasma drift induced by the neutral wind. Note that in the evening sector the midlatitude trough extends across the terminator (1800 MLT) and into sunlight. Such a situation only occurs at this UT, and as will be shown later, produces an interesting $T_{e}$ effect. At $800 \mathrm{~km}$, plasma transport is even more important than at $300 \mathrm{~km}$, and the various $F$ region features are not as distinct.

The ion temperatures that are associated with the electron densities in Figure 3 are shown in Figure 4. At both 180 and 300 $\mathrm{km}$, the ion temperature exhibits very little solar control, and the ion energy balance is mainly determined by ion-neutral interactions. Because of the high electric fields in the dusk sector, an ion "hot spot" is generated. This hot spot results from ion-neutral frictional heating in the region of high electric fields. At low altitudes, this heating mechanism produces ion temperatures that are more than double the neutral temperatures (compare Figures 2 and 4 ); $T_{i}$ reaches $2600 \mathrm{~K}$ in the center of the hot spot at $300 \mathrm{~km}$. The $T_{i}$ distribution is relatively complicated at $800 \mathrm{~km}$, since it depends upon all three previous inputs: neutral density, $T_{n}$ and $N_{e}$. A full description of the ion hot spot as well as the UT variations of $T_{i}$ is given in our previous related studies [Schunk and Sojka, 1982a, b].

As noted earlier, we adopted the model developed by Richards and Torr [1984] to obtain the solar EUV heating rate for the thermal electrons. Figure 5 shows a sequence of heating rate profiles for different solar zenith angles. The four profiles 

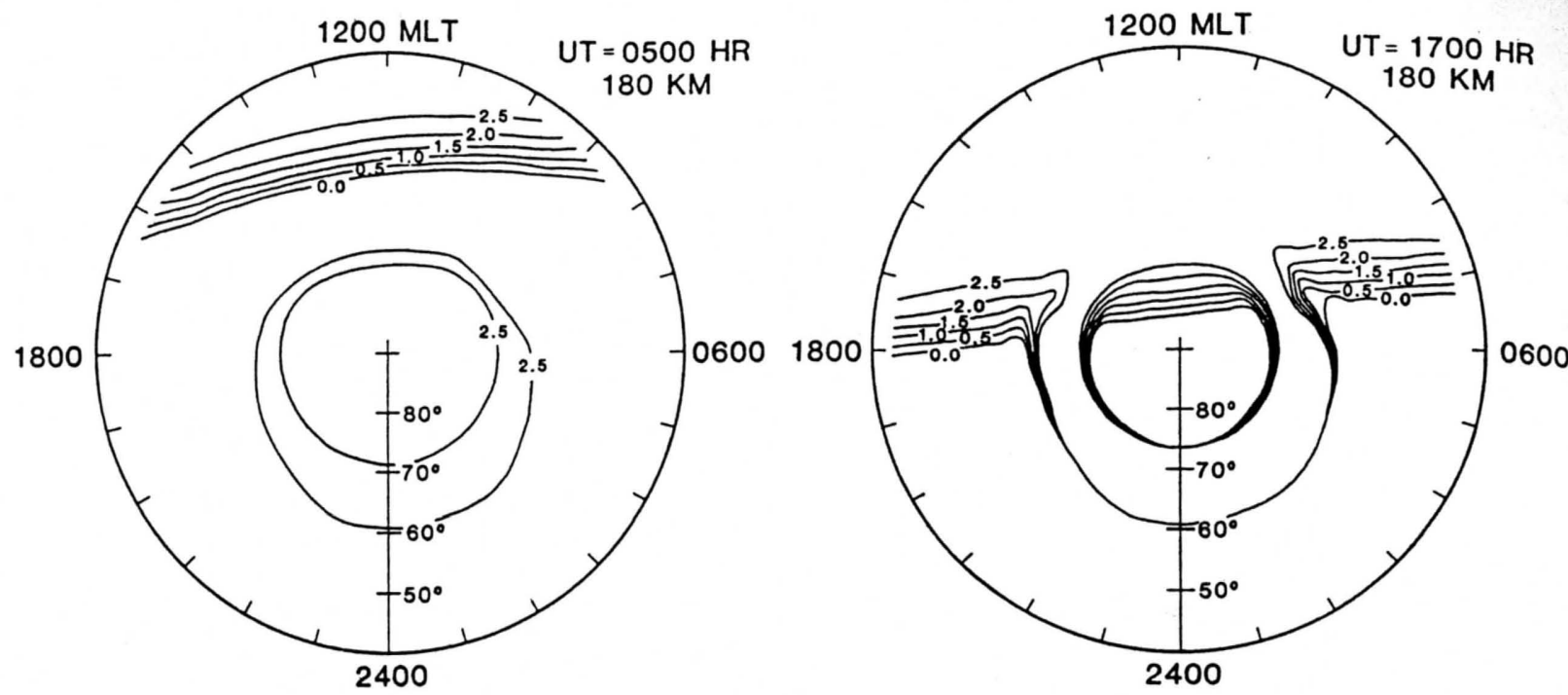

Fig. 6. Contours of the electron heating rate as a function of magnetic latitude and MLT at $180 \mathrm{~km}$ for two universal times. The units are $\mathrm{eV} \mathrm{cm}^{-3} \mathrm{~s}^{-1}$.

shown all lie along the noon meridian. For solar zenith angles greater than $90^{\circ}$, the solar heating rapidly diminishes. Over the $55^{\circ}$ to $90^{\circ}$ range, the peak electron heating rate varies by a factor of about four. As the solar zenith angle increases, the peak heating rate decreases and the altitude of the peak increases. Also shown in Figure 5 is the electron heating rate due to precipitating auroral electrons. This heating rate displays a marked exponential decrease with altitude because we assumed that the precipitating electron spectrum was hard (several keV).

The MLT-magnetic latitude variation of the electron heating rate at $180 \mathrm{~km}$ is shown in Figure 6 for $1700 \mathrm{UT}$ (right panel) and 0500 UT (left panel). Contours of $\log _{10}$ of the heating rate in $\mathrm{eV}$ $\mathrm{cm}^{-3} \mathrm{~s}^{-1}$ are drawn at intervals of 0.5 from 0 up to 2.5. In both panels the auroral oval is clearly evident at a value of about $4 \times$ $10^{2}$. The terminator can be seen to change location as UT changes. At the terminator, the heating rate decreases smoothly over several degrees of latitude. At 1700 UT the terminator overlaps with the auroral oval, but at 0500 UT a significant gap exists between the terminator and oval.

\section{Electron Temperature Variations}

In this section we show how $T_{e}$ varies both with UT and the heat flux through the upper boundary at $800 \mathrm{~km}$.

\subsection{Zero Heat Flux at Upper Boundary}

We first considered the case of no electron heat flow through the upper boundary so that we could clearly assess the relative importance of the solar and auroral heat sources as a function of UT. The resulting electron temperatures are consistent with the electron densities and ion temperatures shown in section 3. Figure 7 shows $T_{e}$ contours at three altitudes for 0500 UT (left panel) and 1700 UT (right panel). At 0500 UT and $180 \mathrm{~km}$ (bottom, left panel), the electron temperature is strongly controlled by local heating rates (compare to Figure 6). On the dayside, $T_{e}$ decreases with increasing solar zenith angle from a high of about $2000 \mathrm{~K}$ to a low of about $800 \mathrm{~K}$. Elevated electron temperatures exist in the auroral oval owing to heating from precipitating electrons, but $T_{e}$ is higher in sunlight than in the auroral oval by about $400 \mathrm{~K}$. Outside of daylight and the auroral oval, $T_{e}$ is strongly coupled to the ions and neutrals, and hence, the values are lower (compare $T_{e}$ with $T_{i}$ in Figure 4 and $T_{n}$ in Figure 2).

At and above $300 \mathrm{~km}, T_{e}$ still has the same auroral oval and dayside features as at $180 \mathrm{~km}$. However, at these higher altitudes an electron temperature hot spot appears in the dusk sector, with $T_{e}$ approaching $2200 \mathrm{~K}$ at $300 \mathrm{~km}$. This region coincides with the location of the ion temperature hot spot (see Figure 4). In this region, the ions are hotter than the electrons, and they transfer heat to the electrons via Coulomb collisions. At $800 \mathrm{~km}$, $T_{e}$ is very similar to that at $300 \mathrm{~km}$, which indicates that $T_{e}$ is approximately constant with altitude. The exception is a region in the dawn sector of the polar cap where $T_{e}$ at $800 \mathrm{~km}$ is about $600 \mathrm{~K}$ hotter than at $300 \mathrm{~km}$. This increase is associated with enhanced electron densities (see Figure 3), which provide a better thermal coupling to the hotter ions.

The right panel of Figure 7 shows the $T_{e}$ contours at $1700 \mathrm{UT}$. At $180 \mathrm{~km}$ (bottom, right panel), the new position of the terminator is evident, as the elevated electron temperatures on the dayside now merge with those in the auroral oval. This feature is also visible at both 300 and $800 \mathrm{~km}$. In addition, at the higher altitudes, new regions of elevated temperatures are present. The electron temperature hot spot at $70^{\circ}$ latitude and $1800 \mathrm{MLT}$ is the one that coincides with the ion temperature hot spot, as seen at $0500 \mathrm{UT}$. The "second $T_{e}$ hot spot" at $65^{\circ}$ latitude and 1600 MLT was not present at $0500 \mathrm{UT}$. In this region, $T_{e}>T_{i}$ and reaches $2600 \mathrm{~K}$. This hot spot coincides with the extension of the mid-latitude trough across the terminator and into sunlight, as noted earlier in connection with Figure 3. As the low electron densities in the trough convect into sunlight, $T_{e}$ increases rapidly owing to the short time constant for heating, while the $N_{e}$ buildup takes much longer.

\subsection{Fixed Heat Flux at Upper Boundary}

The high-latitude ionosphere interfaces with the hot, tenuous, magnetospheric plasma, and a heat flow into the ionosphere is expected. As discussed in the introduction, the magnitude of this heat flux is not known, nor is its variation over the highlatitude ionosphere. In an effort to determine the importance of the magnetospheric heat flux, we calculated electron temperature distributions in the high-latitude ionosphere for a range of 

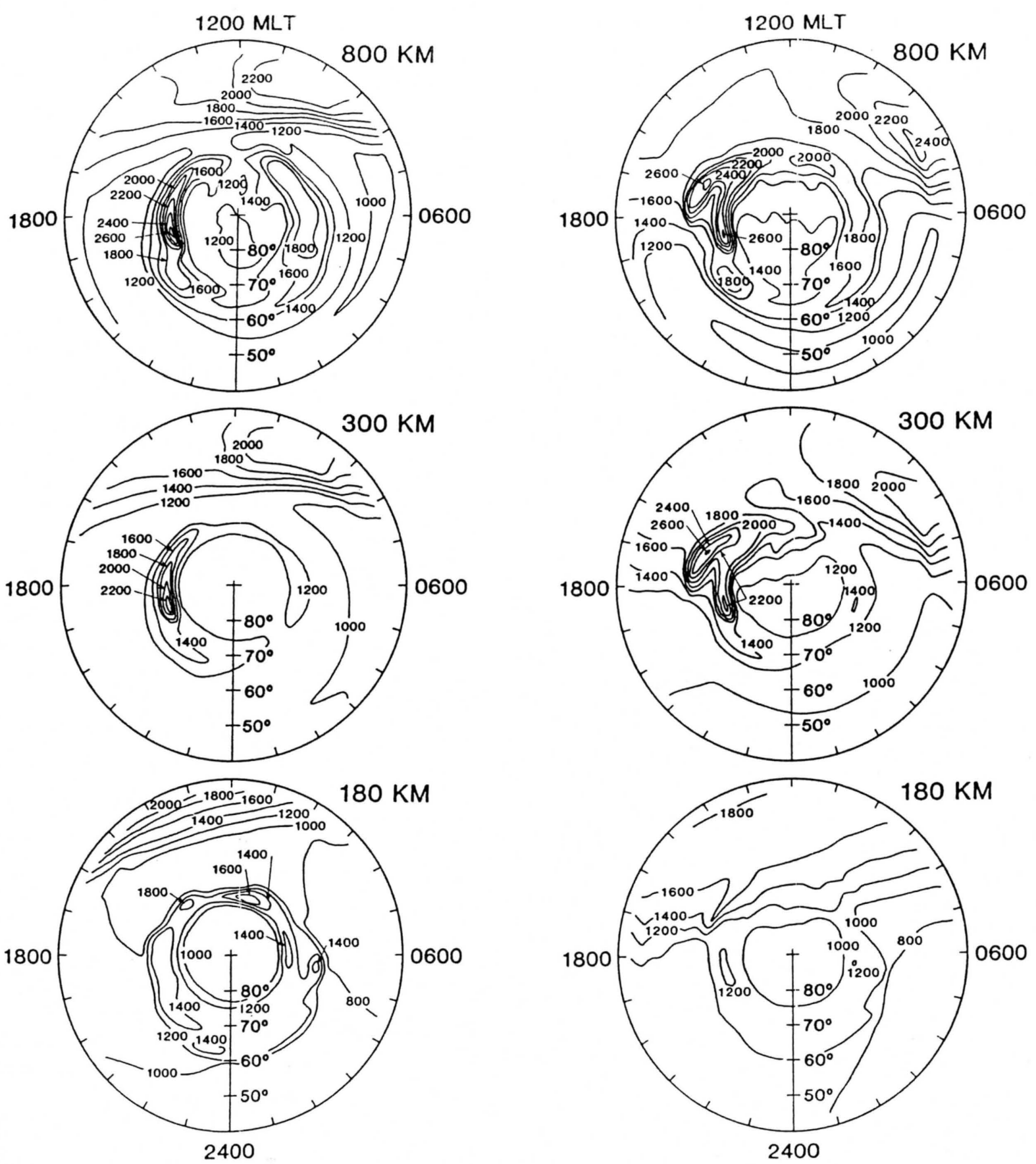

Fig. 7. Contours of electron temperature (K) as a function of magnetic latitude and MLT at three altitudes for 0500 UT (left panel) and 1700 UT (right panel). For these calculations the electron heat flux through the upper boundary was zero.

assumed magnetospheric heat fluxes. However, for these cases we did not calculate consistent ion densities and temperatures because of the extensive computer resources that would be needed. Instead, we used the time-dependent, three-dimensional distributions presented in section 3 for no heat flux at the upper boundary as inputs to the electron energy equation and then obtained new electron temperature distributions for different upper boundary heat fluxes. Since the time constant for electron temperature changes is only a few seconds, the electrons quickly adjust to heat sources, and this aspect causes no difficulties. However, since we did not allow the ion density and temperature distributions to adjust to the new electron temperature distribution, our results are not accurate from the quantitative point of view. Nevertheless, the qualitative behavior of our results is correct.

In this subsection, we compare the $T_{e}$ distribution obtained with a fixed heat flux at the upper boundary of $-1 \times 10^{10} \mathrm{eV}$ $\mathrm{cm}^{-2} \mathrm{~s}^{-1}$ with the case shown previously of no upper boundary heat flux (Figure 7). Figure 8 shows the resulting $T_{e}$ contours at 1700 UT for the same three altitudes as shown in Figure 7. At $180 \mathrm{~km}, T_{e}$ is identical to the 1700 UT case in Figure 7 (right panel), indicating that heat conduction does not penetrate to $180 \mathrm{~km}$. This is not the case at either 300 or $800 \mathrm{~km}$. The dayside and oval temperatures at $300 \mathrm{~km}$ are only slightly elevated, whereas the nightside temperatures are considerably increased. In particular, the nightside mid-latitude trough now has temper- 

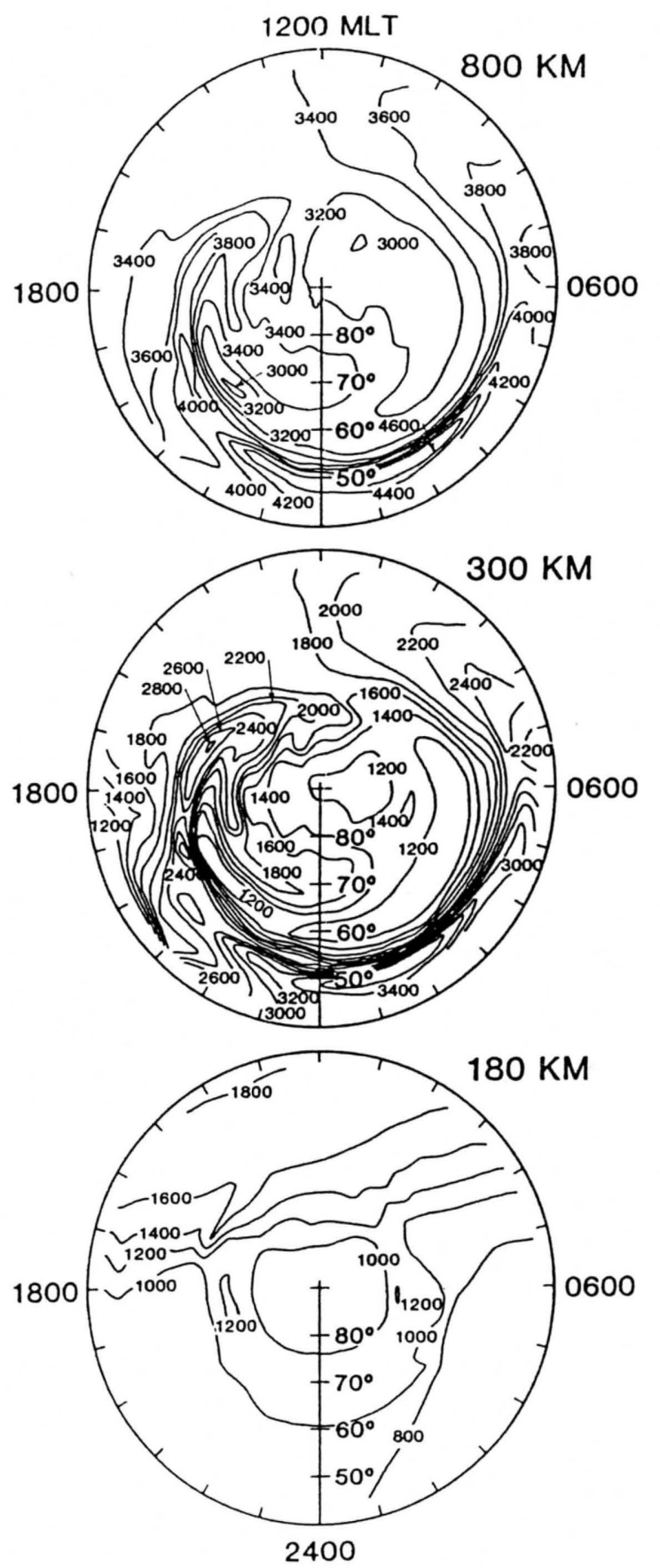

Fig. 8. Contours of electron temperature $(\mathrm{K})$ as a function of magnetic latitude and MLT at three altitudes for 1700 UT. For these calculations the electron heat flux through the upper boundary was $-1 \times 10^{10} \mathrm{eV}$ $\mathrm{cm}^{-2} \mathrm{~s}^{-1}$.

atures over $3600 \mathrm{~K}$ (a factor of 3.5 increase). At $800 \mathrm{~km}$, the whole high-latitude region shows elevated temperatures. These temperatures are sufficiently high that the two hot spots present in Figure 7 at 1700 UT are no longer evident. Indeed, the trough temperatures now exceed the hot spot temperatures by over $1000 \mathrm{~K}$. The peak $T_{e}$ now exceeds $4600 \mathrm{~K}$ in the morning sector trough at $0200 \mathrm{MLT}$. Comparing the zero heat flux case with this case indicates that the whole $T_{e}$ morphology and the absolute temperatures are critically dependent upon the heat flux.

From Figures 7 and 8 it is evident not only that $T_{e}$ varies with location, UT, and heat flux at the top, but that there are significant altitude variations as well. Figure 9 shows electron tempera- ture profiles at a variety of locations for three different cases. Curves 1 and 2 are, respectively, for 0500 and 1700 UT with zero heat flux at the upper boundary, while curve 3 is for 1700 UT with a heat flux of $-1 \times 10^{10} \mathrm{eV} \mathrm{cm}^{-2} \mathrm{~s}^{-1}$. The six locations are listed in Table 2; each location represents a particular morphological region of the high-latitude ionosphere. Panel A is located in the dayside mid-latitude region, and the profiles all show a $T_{e}$ peak near $200 \mathrm{~km}$ that is a characteristic of the mid-latitude ionosphere at solar maximum [Schunk and Nagy, 1978]. The peak is also present poleward of the cusp (panel D) at $1700 \mathrm{UT}$ when this region is sunlit. At $0500 \mathrm{UT}$, when the polar cap is in darkness, $T_{e}$ increases slowly with altitude. No $T_{e}$ peak is present at any of the other four chosen locations.

The UT variation is most marked in the new hot spot (Panel F, Figure 9). Between 0500 and 1700 UT there is a difference of almost $2000 \mathrm{~K}$ at altitudes above $200 \mathrm{~km}$. In contrast, the UT variations of $T_{e}$ in the night sector trough (Panel B), in the auroral oval (Panel C), and in the old hot spot (Panel E) are all less than $50 \mathrm{~K}$. The regions with marked UT effects are associated with changing solar zenith angles. For each location in Figure 9, the effect of the upper boundary heat flux is to increase $T_{e}$ at altitudes above about $250 \mathrm{~km}$. At these higher altitudes, $T_{e}$ increases continuously with altitude in contrast to the zero heat flux upper boundary case, which yielded constant $T_{e}$ profiles on the topside. For the selected locations there is about $1000 \mathrm{~K}$ increase in $T_{e}$ at $800 \mathrm{~km}$ associated with the $-1 \times 10^{10} \mathrm{eV} \mathrm{cm}^{-2}$ $\mathrm{s}^{-1}$ heat flux. This increase reaches $3000 \mathrm{~K}$ in the night sector mid-latitude trough (see Panel B, Figure 9).

\subsection{Variable Heat Flux}

In the previous section we adopted a fixed upper boundary heat flux of $-1 \times 10^{10} \mathrm{eV} \mathrm{cm}^{-2} \mathrm{~s}^{-1}$. This value is somewhat arbitrary, and in reality the heat flux is expected to vary markedly over the polar region. Since no heat flux data are available, we will parametrically study its effect in this section. Figure 10 shows $T_{e}$ profiles for the same six locations in Figure 9. All profiles are for $1700 \mathrm{UT}$, and the locations are defined in Table 2 . The six profiles in each panel correspond to six different upper boundary heat fluxes. These heat fluxes are listed in Table 3. Profile 1 is for zero heat flux, while the third coldest profile is for $-1 \times 10^{10} \mathrm{eV} \mathrm{cm}^{-2} \mathrm{~s}^{-1}$. Above about $200 \mathrm{~km}$, the heat flux controls the $T_{e}$ profile at all locations. The night sector trough temperature exceeds $9000 \mathrm{~K}$ for our maximum heat flux, $-7 \times 10^{10} \mathrm{eV} \mathrm{cm}^{-2} \mathrm{~s}^{-1}$. At the other locations, this heat flux leads to $T_{e}$ values of about $6000 \mathrm{~K}$ at $800 \mathrm{~km}$. For high heat fluxes, the $T_{e}$ profiles are very similar regardless of the location.

Figure 11 shows the electron temperature gradient at $500 \mathrm{~km}$ as a function of heat flux at the upper boundary for the six locations in Figure 10. Each curve is labeled with the index letter from Table 2 . This figure reveals that although a given heat flux yields similar profiles (Figure 10) the actual gradients are significantly different. For a heat flux of $-1 \times 10^{10} \mathrm{eV} \mathrm{cm}^{-2} \mathrm{~s}^{-1}$, the temperature gradient varies from 1.6 to $4 \mathrm{~K} / \mathrm{km}$. Hence, the electron temperature gradient depends strongly upon ionospheric conditions.

\subsection{Possible Heat Flux Variation}

Although the upper boundary heat flux is unknown, its variation over the high latitude can be deduced from simple physical arguments. Auroral regions, which are connected to the hottest region of the magnetosphere, are expected to have much larger downward heat fluxes than the polar cap or mid-latitude 

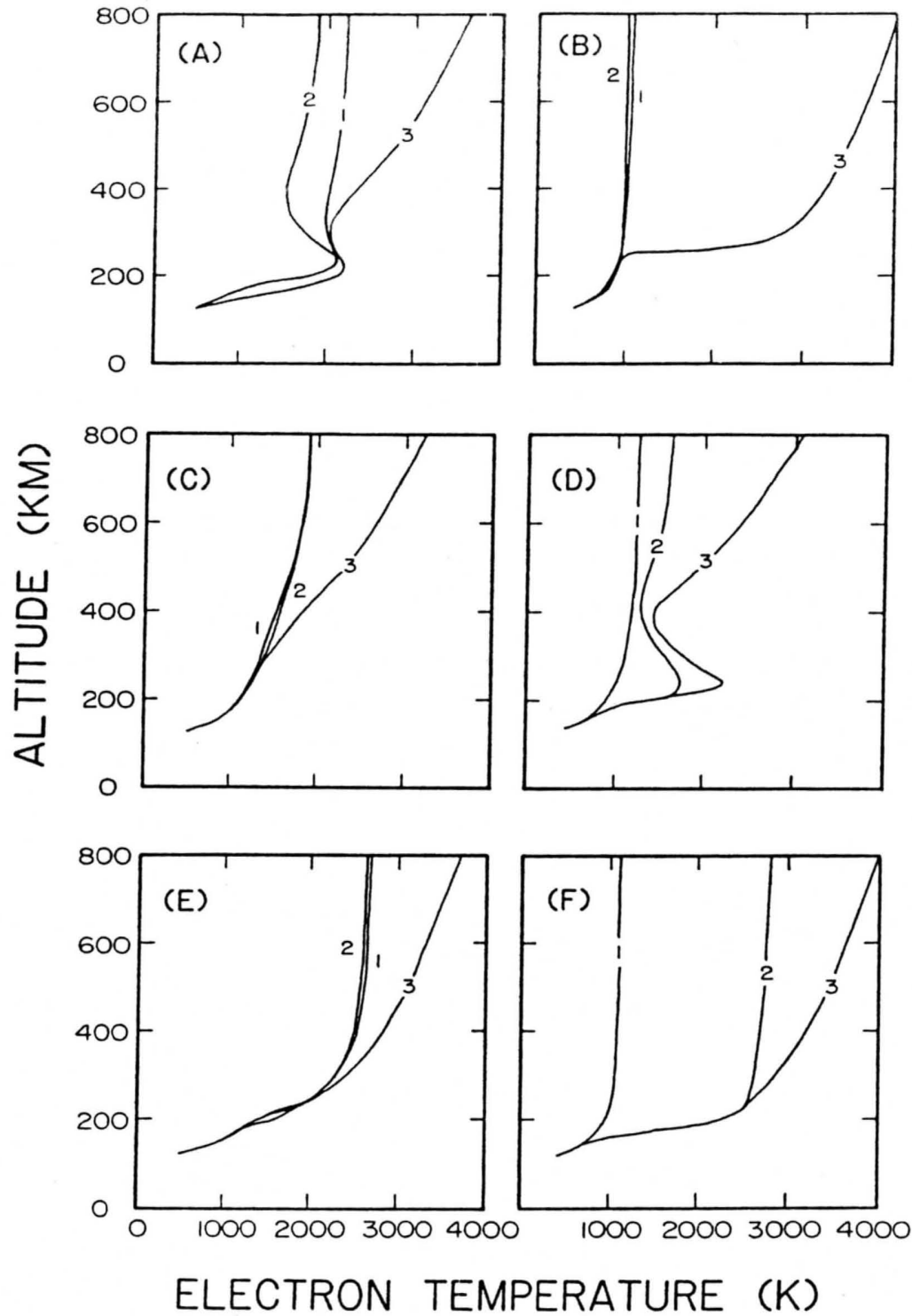

Fig. 9. Altitude profiles of electron temperature (K) at six locations for three cases. Curves 1 and 2 are for 0500 and 1700 UT, respectively, and no heat flux at the upper boundary. Curve 3 is for $1700 \mathrm{UT}$ and a heat flux of $-1 \times 10^{10} \mathrm{eV} \mathrm{cm}^{-2} \mathrm{~s}^{-1}$. Each panel corresponds to a different location, as described in Table 2.

trough. Similarly, sunlit regions are expected to have intermediate heat fluxes because of the topside population of warm photoelectrons. Even within the auroral oval, the cusp region is expected to have a larger downward heat flux than other regions because of the relatively high level of soft precipitation found on these flux tubes. Figure 12 shows a possible upper boundary heat flux variation. In the cusp, the heat flux is taken to be $-3 \times$ $10^{10} \mathrm{eV} \mathrm{cm}^{-2} \mathrm{~s}^{-1}$; the remainder of the oval is $-1 \times 10^{10} \mathrm{eV} \mathrm{cm}^{-2}$ $\mathrm{s}^{-1}$. The dayside shows the heat flux variation at $1700 \mathrm{UT}$; we coupled this to the solar zenith angle variation. Inside the polar cap and on the nightside equatorward of the oval, the heat flux is assumed to be zero.

Figure 13 shows $T_{e}$ contours at three altitudes at $1700 \mathrm{UT}$ for the upper boundary heat fluxes shown in Figure 12. At $180 \mathrm{~km}$, the electron temperature is independent of the upper boundary heat flux (compare with Figure 7, bottom right panel). The two hot spots are still present at $300 \mathrm{~km}$, but at $800 \mathrm{~km}$, only the trough hot spot is visible. In fact, at $800 \mathrm{~km}$ the $T_{e}$ variation reflects the changes in heat flux (compare with Figure 12). The cusp is now the hottest region with temperatures ranging from 3500 to over $4000 \mathrm{~K}$ (see shaded region in the top panel of Figure 13), while the remainder of the auroral oval is at $3000 \mathrm{~K}$. Because of our choice of heat fluxes, the auroral regions are significantly hotter than the other nocturnal regions. On the dayside, the electron temperature increases as the solar zenith angle gets smaller. The $T_{e}$ variations shown in Figure 13 are more like

TABLE 2. Locations for Electron Temperature Profiles

\begin{tabular}{cccl}
\hline & \multicolumn{2}{c}{ Magnetic Coordinates } & \\
\cline { 2 - 3 } Panel in Figure 9 & MLT & Latitude & \multicolumn{1}{c}{ Description } \\
\hline A & 1100 & $44^{\circ}$ & dayside, mid-latitude \\
B & 0300 & $47^{\circ}$ & night sector trough \\
C & 0400 & $71^{\circ}$ & morning sector oval \\
D & 1200 & $80^{\circ}$ & poleward of cusp \\
E & 1900 & $71^{\circ}$ & old hot spot \\
F & 1600 & $65^{\circ}$ & new hot spot \\
\hline
\end{tabular}



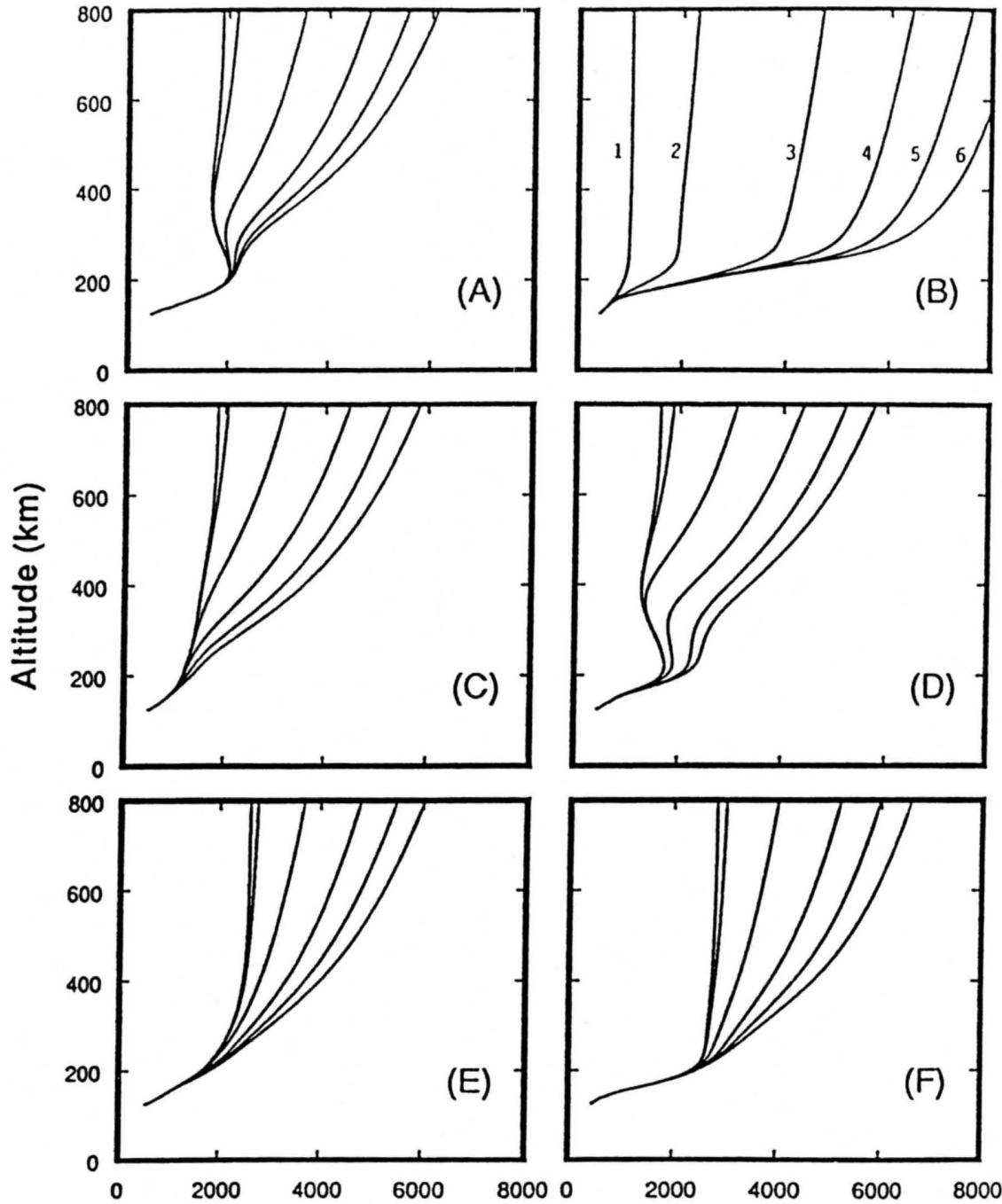

Electron Temperature ( $\mathrm{K}$ K)

Fig. 10. Altitude profiles of electron temperature $(\mathbf{K})$ at six locations for different heat fluxes at the upper boundary. The profiles are for 1700 UT. The locations are given in Table 2 and the heat fluxes in Table 3.

those which could be expected, although the absolute $T_{e}$ values depend sensitively on the value of the upper boundary heat flux.

\section{SUMMARY AND DISCUSSION}

We improved our high-latitude ionospheric model by including the electron energy equation so that we could study the electron temperature behavior at $F$ region altitudes. The adopted energy equation takes account of thermal conduction, thermoelectric transport, heating due to photoelectrons and auroral electrons, Joule heating, thermal coupling to the ions, and both elastic and inelastic cooling to the neutrals.

For our first study using the improved model, we considered solar maximum, winter solstice, and strong geomagnetic activity conditions. The adopted convection pattern was a two-cell pattern with enhanced plasma flow in the dusk convection cell. From this study, we found the following:

1. In general, the UT variation of the electron temperature that results from the displacement between the magnetic and geographic poles is predicted to be only a few hundred degrees, except at the times when low-density regions become illuminated.

2. The model predicts the presence of both $T_{e}$ and $T_{i}$ hot spots in association with a strong convection cell. In this region, ion-neutral frictional heating acts to increase $T_{i}$, which in turn acts to increase $T_{e}$ because of Coulomb interactions $\left(T_{i}>T_{e}\right)$.

3. A second $T_{e}$ hot spot is predicted at the UT when the mid-latitude trough in the dusk sector extends across the terminator and becomes sunlit. In this hot spot, $T_{e}>T_{i}$.

4. The calculations indicate that the dominant parameter controlling the $T_{e}$ variation above $200 \mathrm{~km}$ is the magnetospheric heat flux into the ionosphere, which is essentially unknown.

5. For realistic values of the magnetospheric heat flux, the

TABLE 3. Heat Flux Key for Figure 10

\begin{tabular}{cc}
\hline Curve Label & Heat Flux, $\mathrm{eV} \mathrm{cm}^{-2} \mathrm{~s}^{-1}$ \\
\hline 1 & 0 \\
2 & $-1.0 \mathrm{E} 9 *$ \\
3 & $-1.0 \mathrm{E} 10$ \\
4 & $-3.0 \mathrm{E} 10$ \\
5 & $-5.0 \mathrm{E} 10$ \\
6 & $-7.0 \mathrm{E} 10$ \\
\hline
\end{tabular}

$* 1.0 \mathrm{E} 9=1.0 \times 10^{9}$ 


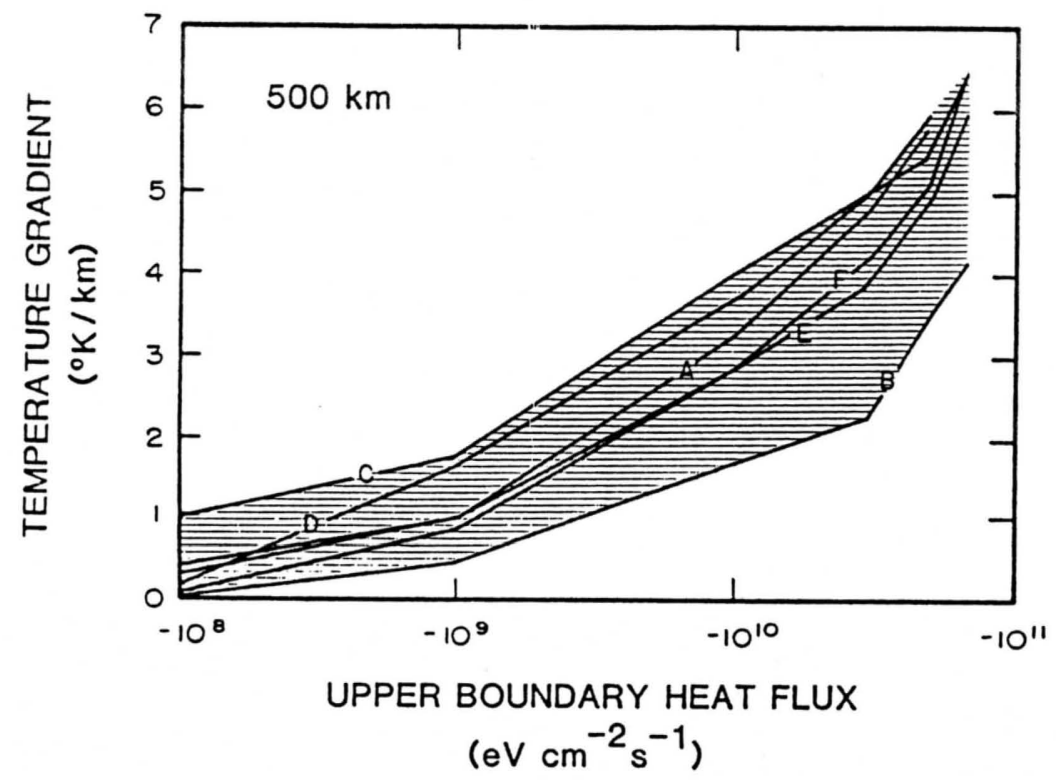

Fig. 11. Electron temperature gradient at $500 \mathrm{~km}$ as a function of the upper boundary heat flux. The letters attached to the curves refer to the locations given in Table 2 .

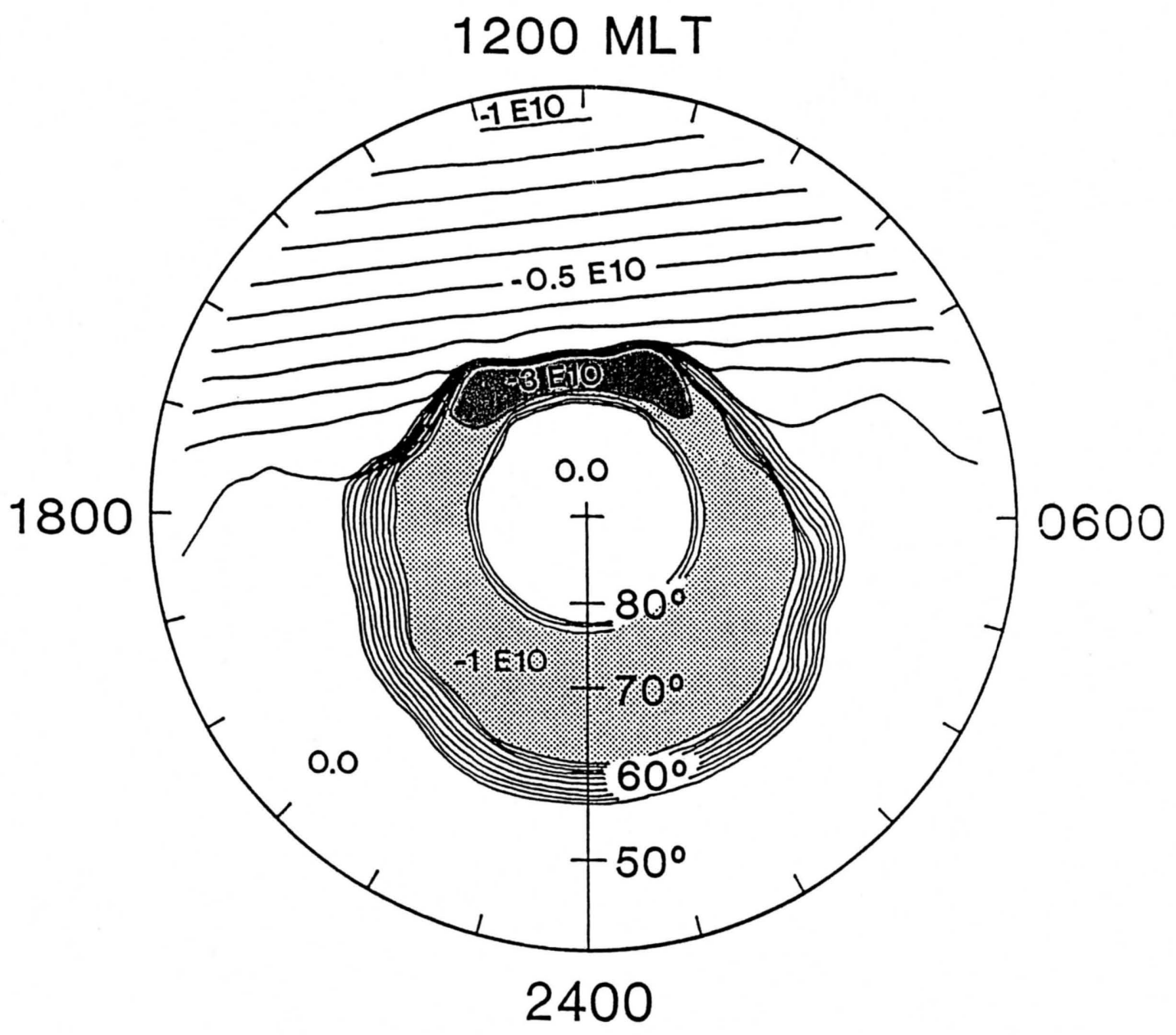

Fig. 12. Upper boundary heat flux $\left(\mathrm{eV} \mathrm{cm}^{-2} \mathrm{~s}^{-1}\right)$ at $1700 \mathrm{UT}$ as a function of magnetic latitude and MLT. 

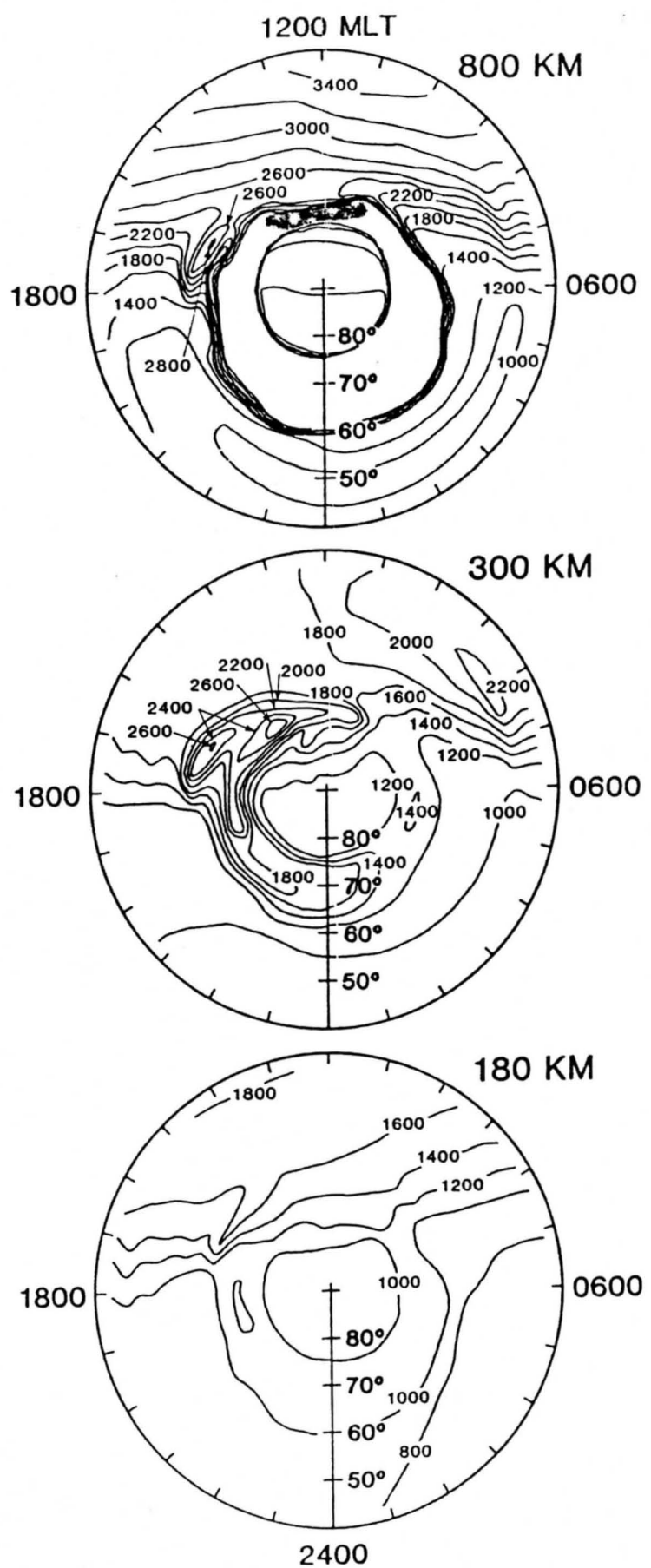

Fig. 13. Contours of electron temperature $(\mathbf{K})$ as a function of magnetic latitude and MLT at three altitudes for 1700 UT. The upper boundary heat fluxes used for these calculations are given in Figure 12. The shaded cusp region contains temperatures greater than $3500 \mathrm{~K}$, with the peak temperature slightly greater than $4000 \mathrm{~K}$.

maximum electron temperature at $800 \mathrm{~km}$ ranges from 5000 to $10,000 \mathrm{~K}$.

6. In general, the electron heat flux at high altitudes is uniquely related to the electron temperature and gradient via $\mathbf{q}_{e}=-7.7 \times 10^{5} T_{e}^{5 / 2} \nabla T_{e} \mathrm{eV} \mathrm{cm} \mathrm{cm}^{-2} \mathrm{~s}^{-1}$, except on auroral field lines where thermoelectric heat flow occurs.

7. For the solar maximum and winter solstice conditions of this study, the $T_{e}$ variation with altitude changed markedly depending on the UT, location, and magnetospheric heat flux.

In this and previous studies, it has been clearly established that the electron temperature in the ionosphere is strongly affected by the neutral densities and temperature, the ion temperature, the electron density, the volume heating rate due to photoelectrons and precipitating auroral electrons, the heat flow conducted down from high altitudes, and the plasma convection pattern. Since these parameters display a marked variation with altitude, latitude, longitude, universal time, season, solar cycle, and geomagnetic activity, the electron temperature is also expected to depend on these parameters. Consequently, a meaningful quantitative comparison of our predictions with observations is possible only if all of the relevant parameters are measured simultaneously at multiple high-latitude locations. Such studies are in progress and will be reported in the near future.

Although a detailed quantitative comparison is not possible at this time, our predicted electron temperatures can be compared in a qualitative fashion with the large body of data collected over the last two decades [cf. Schunk and Nagy, 1978; Wickwar and Kofman, 1984; Curtis et al., 1985; Brace et al., 1982]. These data indicate that $T_{e}$ is higher on the dayside than on the nightside; $T_{e}$ is generally higher in the auroral oval than outside the oval; the maximum values of $T_{e}$ are usually found in the cusp; $T_{e}$ is typically elevated in the trough; and at certain locations, $T_{e}$ can display a significant increase with altitude. Our predicted electron temperatures are in qualitative agreement with all of these trends.

Recently, several empirical models of the ionospheric electron temperature have been developed, and it is useful to qualitatively compare our predictions to these empirical models. Unfortunately, most of these empirical models pertain to the daytime, middle-low-latitude ionosphere, while our results are relevant to the high-latitude ionosphere. Using AE-C satellite data, Brace and Theis [1978] constructed an empirical $T_{e}$ model for the daytime (solar zenith angles less than $85^{\circ}$ ), low-altitude $(130-400 \mathrm{~km})$, middle-low-latitude (between $\pm 50^{\circ}$ ) ionosphere for solar minimum conditions. In a subsequent paper [Brace and Theis, 1981], these authors presented global empirical models of electron temperature in the upper $F$ region and plasmasphere based on AE-C, ISIS 1, and ISIS 2 satellite measurements. Empirical $T_{e}$ models were presented for fixed altitudes of $300,400,1400$, and $3000 \mathrm{~km}$ for solar minimum conditions and for June solstice, December solstice, and equinox. The $T_{e}$ models include diurnal variations and pole-to-pole coverage. Mahajan [1977] constructed empirical $T_{e}$ models using incoherent scatter measurements of $T_{e}$ and $N_{e}$ at Arecibo and St. Santin. The $T_{e}$ models are limited to low altitudes (200-400 km), mid-latitudes, and daytime conditions, but models are presented for both low and medium levels of solar activity. These models were subsequently extended to high altitudes by Mahajan and Pandey [1980]. Thiemann [1980] used AEROS-B satellite data to construct an empirical $T_{e}$ model for the daytime ionosphere at altitudes between 300 and $700 \mathrm{~km}$. Finally, we note that Köhnlein [1981] constructed an empirical $T_{e}$ model for the height range $200-3500 \mathrm{~km}$, for quiet geomagnetic activity, and for solar maximum conditions. The model was constructed using data from the Arecibo, Jicamarca, Millstone Hill, and St. Santin incoherent scatter radars as well as data from the ISIS 1 satellite.

Our theoretical study pertains to the high-latitude ionosphere for solar maximum, winter solstice, and active geomagnetic activity conditions, and therefore, none of the empirical $T_{e}$ models discussed above are directly relevant to our results. Nevertheless, a qualitative comparison is still possible. First, we 
note that at all latitudes, the empirical models show a marked diurnal variation of $T_{e}$ in the $F$ region, which is consistent with our results. Also, for the daytime mid-latitude ionosphere, the empirical models indicate that $T_{e}$ is essentially independent of $N_{e}$ below $200 \mathrm{~km}$, but varies inversely with $N_{e}$ at higher altitudes. For comparison, we found that at high latitudes, $T_{e}$ varies inversely with $N_{e}$ at high altitudes as it does at midlatitudes, but $T_{e}$ is not always independent of $N_{e}$ below $200 \mathrm{~km}$ in the high-latitude ionosphere. In particular, in regions of strong plasma convection, the ion temperature can be significantly enhanced below $200 \mathrm{~km}$, and depending on the electron density, the thermal coupling between the ions and electrons can lead to elevated electron temperatures.

At high latitudes, the $T_{e}$ data used to construct the empirical models show an appreciable scatter even for the same geophysical conditions. For example, in the daytime high-latitude ionosphere at $500 \mathrm{~km}$ and for low geomagnetic activity, the $T_{e}$ values vary from 1000 to $3000 \mathrm{~K}$ [Thiemann, 1980]. If strong geomagnetic activity conditions were considered, the scatter in $T_{e}$ probably would have been larger. Nevertheless, our daytime values at $500 \mathrm{~km}$ fall within this range for topside heat fluxes less than about $-1 \times 10^{10} \mathrm{eV} \mathrm{cm}^{-2} \mathrm{~s}^{-1}$ (see Figures 7, 8, 10, and 13). With regard to the empirical model of Brace and Theis [1981], $T_{e}$ values ranging from 1500 to $2500 \mathrm{~K}$ are obtained in the winter high-latitude ionosphere at $400 \mathrm{~km}$. However, the actual $T_{e}$ values that produced the empirical model varied from a factor of 2 lower to a factor of 2 higher than the model values. Consequently, almost all of our cases fall within this $T_{e}$ range; only for very large upper boundary heat fluxes do our predicted $T_{e}$ values go beyond this range.

Acknowledgments. This research was supported by NASA grant NAGW -77 and National Science Foundation grant ATM-8417880 to Utah State University. The computer modeling effort was supported by the National Center for Atmospheric Research, which is sponsored by the National Science Foundation.

The Editor thanks V. Wickwar and another referee for their assistance in evaluating this paper.

\section{REFERENCES}

Banks, P. M., Collision frequencies and energy transfer, electrons, Planet. Space Sci., 14, 1085-1102, 1966.

Brace, L. H., and R. F. Theis, An empirical model of the interrelationship of electron temperature and density in the daytime thermosphere at solar minimum, Geophys. Res. Lett., 5, 275-278, 1978.

Brace, L. H., and R. F. Theis, Global empirical models of ionospheric electron temperature in the upper $F$-region and plasmasphere based on in situ measurements from the Atmosphere Explorer-C, ISIS-1, and ISIS-2 satellites, J. Atmos. Terr. Phys., 43, 1317-1343, 1981.

Brace, L. H., R. F. Theis, and W. R. Hoegy, A global view of $F$-region electron density and temperature at solar maximum, Geophys. Res. Lett., 9, 989-992, 1982.

Crank, J., and P. Nicolson, A practical method for numerical evaluation of solutions of partial differential equations of the heatconduction type, Proc. Cambridge Philos. Soc., 43, 50-67, 1947.

Curtis, S. A., W. R. Hoegy, L. H. Brace, and J. D. Winningham, Cusp altitudinal electron temperature gradient: Dynamics Explorer 2 implications for heating mechanisms, J. Geophys. Res., 90, 44154419, 1985.

Dalgarno, A., Collisions in the ionosphere, Adv. At. Mol. Phys., 4, $381-410,1968$.

Feldstein, Y. I., and G. V. Starkov, Dynamics of auroral belt and polar geomagnetic disturbances, Planet. Space Sci., 15, 209-229, 1967.

Hedin, A. E., J. E. Salah, J. V. Evans, C. A. Reber, G. P. Newton, N. W. Spencer, D. C. Kayser, D. Alcayde, P. Bauer, L. Cogger, and J. P. McClure, A global thermospheric model based on mass spectrometer and incoherent scatter data, MSIS $1, \mathrm{~N}_{2}$ density and temperature, $J$. Geophys. Res., 82, 2139-2147, 1977a.

Hedin, A. E., C. A. Reber, G. P. Newton, N. W. Spencer, H. C. Brinton, H. G. Mayr, and W. E. Potter, A global thermospheric model based on mass spectrometer and incoherent scatter data, MSIS 2, Composition, J. Geophys. Res., 82, 2148-2156, $1977 b$.

Henry, R. J. W., and M. B. McElroy, Photoelectrons in planetary atmospheres, in The Atmospheres of Venus and Mars, edited by J. C. Brandt and M. B. McElroy, pp. 251-285, Gordon and Breach, New York, 1968.

Henry, R. J. W., P. G. Burke, and A. L. Sinfailam, Scattering of electrons by C, N, O, $\mathrm{N}^{+}, \mathrm{O}^{+}$, and $\mathrm{O}^{++}$, Phys. Rev., 178, 218-225, 1969.

Hoegy, W. R., New fine structure cooling rate, Geophys. Res. Lett., 3, 541-544, 1976.

Kofman, W., and V. B. Wickwar, Very high electron temperatures in the daytime $F$ region at Sondrestrom, Geophys. Res. Lett., 11, 919-922, 1984.

Köhnlein, W., Electron temperature variations during solar maximum conditions (200-3500 km), Planet. Space Sci., 29, 47-56. 1981.

Mahajan, K. K., Models of electron temperature in the ionospheric F-region using electron density height profiles, J. Atmos. Terr. Phys., 39, 637-639, 1977.

Mahajan, K. K., and V. K. Pandey, Models of electron temperature in the topside ionosphere for low and medium solar activity conditions, J. Geophys. Res., 85, 213-216, 1980.

Murphy, J. A., G. L. Bailey, and R. J. Moffett, Calculated daily variations of $\mathrm{O}^{+}$and $\mathrm{H}^{+}$at mid-latitudes, J. Atmos. Terr. Phys., 38, 351-364, 1976.

Prasad, S. S., and D. R. Furman, Electron cooling by molecular oxygen, J. Geophys. Res., 78, 6701-6707, 1973.

Rees, M. H., R. A. Jones, and J. C. G. Walker, The influence of field-aligned currents on auroral electron temperatures, Planet. Space Sci., 19, 313-325, 1971.

Richards, P. G., and D. G. Torr, An investigation of the consistency of the ionospheric measurements of the photoelectron flux and solar EUV flux, J. Geophys. Res., 89, 5625-5635, 1984.

Schunk, R. W., and A. F. Nagy, Electron temperatures in the $F$ region of the ionosphere: Theory and observations, Rev. Geophys., 16, 355-399, 1978.

Schunk, R. W., and A. F. Nagy, Ionospheres of the terrestrial planets, Rev. Geophys., 18, 813-852, 1980.

Schunk, R. W., and W. J. Raitt, Atomic nitrogen and oxygen ions in the daytime high-latitude $F$ region, J. Geophys. Res., 85, 1255-1272, 1980.

Schunk, R. W., and J. J. Sojka, Ion temperature variations in the daytime high-latitude $F$ region, $J$. Geophys. Res., 87, 5169-5183, $1982 a$.

Schunk, R. W., and J. J. Sojka, Ionospheric hot spot at high latitudes, Geophys. Res. Lett., 9, 1045-1048, 1982 .

Schunk, R. W., and J. C. G. Walker, Transport properties of the ionospheric electron gas, Planet. Space Sci., 18, 1535-1550, 1970.

Schunk, R. W., and J. C. G. Walker, Theoretical ion densities in the lower ionosphere, Planet. Space Sci., 21, 1875-1896, 1973.

Schunk, R. W., W. J. Raitt, and P. M. Banks, Effect of electric fields on the daytime high-latitude $E$ and $F$ regions, J. Geophys. Res., 80, 3121-3130, 1975.

Schunk, R. W., P. M. Banks, and W. J. Raitt, Effects of electric fields and other processes upon the nighttime high-latitude $F$ layer, $J$. Geophys. Res., 81, 3271-3282, 1976.

Sojka, J. J., and R. W. Schunk, A theoretical study of the high latitude $F$ region's response to magnetospheric storm inputs, J. Geophys. Res., $88,2112-2122,1983$.

Sojka, J. J., W. J. Raitt, and R. W. Schunk, Effect of displaced geomagnetic and geographic poles on high-latitude plasma convection and ionospheric depletions, J. Geophys. Res., 84, 5943-5951, 1979.

Sojka, J. J., J. C. Foster, W. J. Raitt, R. W. Schunk, and J. R. Doupnik, High-latitude convection: Comparison of a simple model with incoherent scatter observations, J. Geophys. Res., 85, 703-709, 1980.

Sojka, J. J., W. J. Raitt, and R. W. Schunk, A theoretical study of the high-latitude winter $F$ region at solar minimum for low magnetic activity, J. Geophys. Res., 86, 609-621, 1981a.

Sojka, J. J., W. J. Raitt, and R. W. Schunk, Plasma density features associated with strong convection in the winter high-latitude $F$ region, J. Geophys. Res., 86, 6908-6916, 1981 b.

Sojka, J. J., R. W. Schunk, and W. J. Raitt, Seasonal variations of the high-latitude $F$ region for strong convection, J. Geophys. Res., 87, 187-198, 1982.

Sojka, J. J., R. W. Schunk, J. V. Evans, J. M. Holt, and R. H. Wand, Comparison of model high-latitude electron densities with Millstone Hill observations, J. Geophys. Res., 88, 7783-7793, 1983. 
Stubbe, P., and W. S. Varnum, Electron energy transfer rates in the ionosphere, Planet. Space Sci., 20, 1121-1126, 1972.

Thiemann, H., Structure of electron temperature, in The Physical Basis of the Ionosphere in the Solar-Terrestrial System, AGARD Conf. Proc., 295, 24.1-24.9, 1980.

Volland, H., Models of global electric fields within the magnetosphere, Ann. Geophys., 31, 159-161, 1975.

Volland, H., A model of the magnetospheric electric convection field, $J$. Geophys. Res., 83, 2695-2699, 1978.

Wickwar, V. B., and W. Kofman, Dayside red auroras at very high latitudes: The importance of thermal excitation, Geophys. Res. Lett., 11, 923-926, 1984.

M. D. Bowline, R. W. Schunk, and J. J. Sojka, Center for Atmospheric and Space Sciences, Utah State University, Logan, UT 84322.

(Received February 17, 1986; revised May 30, 1986; accepted June 20, 1986.) 